\title{
Predicting the Roles of Attitudes and Self-Efficacy in Readiness Towards Implementation of Inclusive Education Among Primary School Teachers
}

\author{
Nurulhana Zainalabidin ${ }^{1}$, Aini Marina Ma'rof ${ }^{1}$ \\ ${ }^{1}$ Faculty of Educational Studies, Universiti Putra Malaysia, Serdang, Selangor, Malaysia \\ Correspondence: Aini Marina Ma'rof, Faculty of Educational Studies, Universiti Putra Malaysia, 43400 UPM \\ Serdang, Selangor, Malaysia. Tel: 603-9769-8210. E-mail: ainimarina@upm.edu.my
}

Received: September 3, 2021

Accepted: September 28, $2021 \quad$ Online Published: October 15, 2021

doi:10.5539/ass.v17n11p91

URL: https://doi.org/10.5539/ass.v17n11p91

\begin{abstract}
Teachers' preparedness is a critical component in implementing inclusive education. It is pertinent to understand whether mainstream instructors are ready for inclusion as the number of children with special needs increases steadily over the years. The Zero Reject Policy has accelerated the implementation of inclusive education in Malaysia. While this is an essential step forward, assessing teachers' readiness for change is critical. This study aims to find out the predictive factors (attitudes and self-efficacy) on the preparedness of mainstream primary school teachers towards the implementation of inclusive education. This study is of a correlational research design where questionnaires were distributed to 367 teachers randomly selected from a cluster of nine schools in Hulu Selangor, Malaysia. The results show that teachers have moderate levels of readiness, attitudes and self-efficacy. There are also significantly positive relationships and predictive correlations between attitudes and readiness as well as self-efficacy and readiness. This implies that attitudes and self-efficacy should be considered in gauging teachers' readiness in the implementation of inclusive education. Taken together, findings in this study could inform further inclusive education research in Malaysia and could be taken into consideration in the design and execution of teacher training courses on Inclusive Education.
\end{abstract}

Keywords: inclusive education, teacher readiness, attitudes, self-efficacy

\section{Introduction}

Learning disorders are showing a steady increase in Malaysia. Ching (2009) asserts that in 2004, there were 57,483 children with special educational needs (SEN), and in 2009, there was an increase to 100,180. In five years, the growth shown is indeed rather alarming. Malaysian education Statistics (MOE, 2018) presented an increase in enrollment figures of SEN children from 48140 in 2010, 50738 children in 2012, to 79836 in 2017. MOE (2017) reported that $78 \%$ of children are in integration programs, while a small portion (19\%) attend the inclusive education program, and $3 \%$ of the students are in special schools. There is still more work to implement inclusive education, one of the key goals in the Malaysian Education Blueprint, to have $75 \%$ of SEN children in inclusive education by 2025 .

The Salamanca Statement (1994) stated that participation and inclusion are salient to human dignity and the exercise of human rights. Therefore, there is a need to reflect on strategy development within the education field to achieve genuinely equalised opportunity for every child. Both policies advocate that all children have access to an education that is inclusive. The Zero Reject Policy ensures that all undocumented and special needs children have access to education and is planned to be implemented by stages (New Straits Times, 2018). The Zero Reject Policy is a majorly crucial albeit bold step to ensure that the educational system includes and supports all students, particularly students with SEN in Malaysia. Inclusion has attained ground over the past decade internationally (Leonard \& Smyth, 2020; Azorin \& Ainscow, 2020; Black \& Simon, 2014; Waitoller \& Artiles, 2013). The Education 2030 initiative marks a significant step forward, in which the priority is presented clearly: to establish equitable and inclusive quality education and encourage opportunities for lifelong learning for all (UNESCO, 2015). Inclusive education requires equal opportunities for every child to be educated in a mainstream classroom irrespective of their special educational needs (Goodall, 2015).

Teachers have been increasingly called upon to adopt inclusive practices in teaching regarding the needs of all 
students (Saloviita, 2020; Azorin \& Ainscow, 2020). However, the teachers' readiness and willingness to make the adjustments are often unmeasured as an essential precondition for teachers to undertake such a task (Rouse, 2018). Di Gennaro et al. (2014) suggests that teachers should learn ways to value difference and the best methods in responding to diversity in their classrooms. However, readily available knowledge for teachers would unlikely be applied if they lack the will to do so. It might be because they do not believe the inclusion of all learners is their role, or they think that their actions would not lead to positive results for all students (Rabi et al., 2018).

Moreover, teachers with negative attitudes and low self-efficacy are more likely to be more frustrated and lack the confidence to implement inclusive practices in their teaching (Agbenyega \& Klibthong, 2015; Subban, Round, \& Sharma, 2021). Hence, it is critical for instructors to have favourable attitudes toward inclusion and high levels of self-efficacy to successfully administer inclusive education (Hashim, Ghani, Ibrahim, \& Zain, 2014). Therefore, teacher education courses that focus on inclusive issues can transform teachers' attitudes and self-efficacy besides providing knowledge to teachers (Killoran, Woronko, and Zaretsky, 2014) to be more prepared to teach in inclusive settings.

Readiness involves combining a person's ability and willingness to perform tasks that indicate a situational need for different leadership approaches (Baker, 2002). Hay, Smith and Paulsen (2001) argue that teacher readiness involves getting teachers ready for change. In the context of an organisation, change entails a loss of established practices, a movement from expert to student, and a shift in power dynamics (Ricci et al., 2020). As school administrators question the current status quo to disrupt settings that promote marginalisation of groups of children based on their many characteristics of learning capacity, they can expect opposition (Black \& Simon, 2014). Sofian et al. (2020) assert that teachers would heavily impact the learning process and the development of SEN students, thus are also responsible for the successful implementation of inclusive education. They believed that greater drive, energy, creativity are required from teachers involved in teaching special education. An inclusive classroom does not signify that a child is placed in a mainstream classroom with typically developing peers but are ignored or not being provided equal opportunity to thrive in their learning environment, as do their typically developing peers.

Conversely, an inclusive classroom is where SEN students are included in a mainstream classroom, providing services to the teachers and the students to fully participate in academic and extracurricular activities (Shevlin et al., 2013). Sharma and George (2016) argue that attitudes and self-efficacy influence teachers' responses and behaviours towards inclusive education rather than one of those two constructs. They stated that teachers who possess a high sense of self-efficacy, have positive attitudes towards inclusive education and teach in schools where they are adequately supported might be more willing to include students with SEN. Hence, teachers need to have positive attitudes and high self-efficacy to be ready for inclusive education.

Corsini \& Auerbach (1998) define attitude as a stable and learned disposition in a favourable or unfavourable response to a person, an object or event in a consistent manner. The attitude was previously viewed as a single factor. However, Rosenbergcor and Hovland (1960) distinguished the three-component attitude model, including cognitive, affective and behavioural elements. A key reason for studying attitudes is that attitudes are the best predictors of behavioural intentions (Ajzen and Fishbein 1980). Attitudes concerning readiness have been an exciting area of study. Often, teachers might have positive attitudes about SEN students and inclusive education in general but still, feel unprepared to teach students with SEN. Buford and Casey (2012), in their study, found that teachers showed overall positive attitudes. Still, there were substantial implications that training was needed, so teachers are more ready and willing to adopt inclusive practices in their classrooms. Previous research shows that teachers with more positive views of inclusion display more self-efficacy and confidence in their ability to support students with disabilities and be prepared to adapt classroom materials and procedures to accommodate their needs (Beacham and Rouse, 2012; Florian and Black-Hawkins 2011; Sharma, Forlin, and Loreman 2008). In studies on teachers' attitudes towards inclusive programs that have been carried out in Malaysia, many teachers expressed ambivalent feelings towards Inclusive Education teaching experiences (Ali et al., 2006; Bailey et al., 2015; Sukumaran et al., 2015). Findings in this study could strengthen the assumption that ambivalent feelings might exist as teachers do not have enough knowledge of inclusive practices to form their opinions.

Self-efficacy is a future-oriented perception and belief associated with one's competence level that they might portray in situations that affect emotions and thoughts (Bandura, 1997). Schunk and Pajares (2005) articulate that self-efficacy is a person's perceived ability and confidence in organising and executing a predetermined set of actions to accomplish a task and find solutions to a problem. Bandura (1997) stated that teachers' self-efficacy impacts the type of environment that teachers can create for learners and their perceptions on the variation of 
teaching tasks that they would be willing to perform to improve students' learning process. Bandura (1990) suggests that a teacher's competence includes knowledge and skills and being able to apply them successfully in various situations and diverse circumstances, and many of which involve stressful and unpredictable elements. Therefore, a high degree of self-efficacy would impact teachers' willingness to be immersed in positive, inclusive behaviours, bringing about positive differences in teacher attitudes (Cate, Markova, Krischler, \& Krolak-Schwerdt, 2018).

Furthermore, educators with high efficacy are more willing and prepared to provide accommodations and modifications for SEN students (MacFarlane \& Woolfson, 2013; Umhoefer, Beyer, and Vargas). Teachers with high efficacy beliefs can successfully identify and are subsequently more prepared to address challenges in the inclusive classroom. They are also more willing to develop instructional approaches that are most effective for their learners with diverse needs (MacFarlane \& Woolfson, 2013; Umhoefer et al., 2013).

Through inclusive education, teachers can provide adequate support to students in nurturing them to become capable citizens. Inclusive education involves a paradigm shift in thinking about the social world and the education system (Marimuthu \& Cheong, 2014). The study's findings are vital to provide evidence and determine the predictive roles of attitudes and self-efficacy in readiness among mainstream teachers. The study reflects meaningful insights on attitudes and self-efficacy in regards to preparedness. The predictive relationships in this study can be of reference to local and international researchers. Studies showed that local researchers primarily focused on policies and practices in the inclusive program, teachers' attitudes and self-efficacy in separate studies (Teng, 2016). Since there are theoretical and practical connections between the variables in this study, it is worth exploring their relationship to yield meaningful contributions to the inclusive education field locally and internationally. The Zero Reject Policy would eventually involve increasing Malaysian schools adopting the inclusive education model, so it is crucial to analyse teachers' readiness and factors that influence it. Establishing these baseline levels should essentially include rural areas and small towns like the Hulu Selangor area, where there are fewer teachers in each school (the minimum number of teachers in a school was 14 teachers in the sample size) and fewer students. Schools with smaller teachers and students need to be considered as they, too, would be part of the statistics in gauging the readiness to implement inclusive education and its success.

The study's theoretical basis entails predicting the roles of two predictor factors (attitudes and self-efficacy) in the level of preparedness (criterion variable) among teachers in mainstream primary schools in Hulu Selangor, Malaysia. A sample of 367 mainstream teachers was selected from a cluster of 9 Hulu Selangor mainstream public schools. First, a survey was conducted, which included four parts. Part A contains demographic information about teachers; part B consists of the Scale of Teachers' Attitudes towards Inclusive Classrooms (Static), containing 20 items; and part C on Teacher's Self Efficacy for Inclusive Practices (TEIP), which includes 35 items. Finally, part D is 20 items measuring teachers' readiness to implement the inclusive education program, modified from Lee and Low (2013).

Research Objectives

The objectives of this study are:

1. To investigate the levels of attitudes, self-efficacy, and readiness towards implementing inclusive education among mainstream primary school teachers.

2. To investigate the relationship between attitudes and readiness towards implementing inclusive education among mainstream primary school teachers.

3. To investigate the relationship between self-efficacy and readiness towards implementing inclusive education among mainstream primary school teachers.

4. To investigate the predicting roles of attitudes and self-efficacy on readiness to implement inclusive education among mainstream primary school teachers.

\section{Methods}

This descriptive quantitative research takes the form of a predictive correlational study. Its primary purpose is to predict the roles of self-efficacy and attitudes in readiness towards implementing inclusive education among mainstream primary school teachers in Hulu Selangor, Malaysia. This study utilised a survey design in which questionnaires were administered to teachers from mainstream primary schools. The predictor variables are attitudes and self-efficacy, and the criterion variable is readiness among teachers.

\subsection{Participants and Procedure}

A sample of 367 mainstream teachers was selected from 9 mainstream public schools in Hulu Selangor, 
Malaysia after a cluster of simple random sampling was carried out to determine the schools. The developers of the instruments were contacted to obtain permission to use and modify the measures in this study.

\subsection{Instrument}

By using three measures, this study examines data on attitudes, self-efficacy, and preparedness to adopt inclusive education among mainstream primary school teachers. The following is a list of instruments and their descriptions, as well as the score:

Scale of Teacher's Attitudes towards Inclusive Classrooms (Static). Cochran created the Static scale measuring teacher attitudes about inclusive schools (1998). The scale consists of 20 items on which teachers' opinions about the inclusion of children with SEN in classrooms are rated on a 5-point Likert scale ranging from (1) strongly disagree to (5) strongly agree. There are no particular cut-off values; high scores indicate good attitudes, and low numbers reflect negative views of the teacher. In addition, STATIC had subscales for advantages and drawbacks of inclusive education, professional difficulties, philosophical questions, and logistical considerations, according to Cochran (1998).

Teacher's Self Efficacy for Inclusive Practices (TEIP). Sharma et al. created the Teacher Self-Efficacy for Inclusive Practice Scale (2015). The scale was divided into three subscales by Sharma et al. (2012): 1) Self-efficacy in instruction, which assesses students' ability to use successful techniques in a diverse classroom. 2) Efficacy in cooperation assesses participants' self-perceptions of their ability to collaborate with students, parents, and other staff members. 3) Behavior management efficacy contains questions that assess participants' self-efficacy in dealing with students' problematic behaviours and concerns. A 6 item Likert scale, ranging from (1) strongly disagree to (6) strongly agree, is used to evaluate 35 items that focus on teachers' self-efficacy in including all learners in the classroom.

Readiness of Teachers. Lai et al. (2017) conducted a study to investigate the level of preparedness among mainstream teachers in teaching in an Inclusive Education Program (IEP). The study's objective is to examine readiness levels of mainstream teachers in terms of their teaching skills, attitudes, and field knowledge. A questionnaire was developed by Lai et al. (2017) based on the objectives of the study. It contains 35 items, and participants rate their responses on a 5 point Likert scale ranging from (1) strongly disagree to (5) strongly agree. The questionnaire was classified into three subscales: Readiness level in terms of teaching skills, readiness level based on teacher's attitudes and readiness in terms of field knowledge. This instrument was modified for this study. Since an attitude scale is already used to measure teachers' attitudes, the subscale of readiness level in terms of perspectives will be omitted in this study. Instead, the instrument in the study would include 20 items based on the subscale of readiness level in terms of teaching skill and readiness level in terms of field of knowledge.

\subsection{Reliability}

A Cronbach alpha test was conducted to test the reliability of the items. According to the test, the results need ( $\alpha>$ $0.7)$ for the reliability to be acceptable and high. The attitude subscale consists of 19 items $(\alpha=.709)$, after 1 item is deleted (item 12) in order to achieve ( $\alpha>0.7$ ha). The self-efficacy subscale consisted of 17 items ( $\alpha$ $=.707$ ), after 1 item was deleted (item 9) to achieve $(\alpha>0.7)$. The readiness subscale consisted of 20 items ( $\alpha$ $=.942)$ with no items deleted.

\section{Results}

\subsection{Levels of Attitudes, Self-efficacy and Readiness Towards the Implementation of Inclusive Education}

The levels of attitudes, self-efficacy and readiness of mainstream primary school teachers towards inclusive education are calculated using mean and standard deviation. The average of attitude score is $3.10(\mathrm{SD}=.38)$, average self-efficacy score is $3.75(\mathrm{SD}=.40)$ and average of readiness score is $3.22(\mathrm{SD}=.65)$.

The attitudes, self-efficacy, and readiness levels are determined by dividing the mean range by the number of levels (low, moderate, high). The ranges for attitude levels are classified as: 1.87-2.55 (low), 2.56-2.23 (moderate), and 3.24-3.91 (high). The ranges for self-efficacy levels are: 2.69-3.19 (low), 3.80-4.38 (moderate) and 3.80-4.38 (high), and the ranges for levels of readiness are 2.33-2.84 (low), 2.85-3.36 (moderate). 3.37-2.87 (high). The average mean of attitude, self-efficacy and readiness is at a moderate level.

The highest mean score for teacher attitudes is item A6, with a mean score of 3.91 (SD =1.02). The lowest mean score is A7 1.87 ( $\mathrm{SD}=1.04)$, "I believe that children with special needs should be placed in special education classes". The highest mean score for self-efficacy of teachers is $4.38(\mathrm{SD}=1.05)$ for item B15" (e.g., portfolio assessment, modified tests, performance-based assessment, etc.)". The lowest mean score is item B4 2.60 (SD = 
1.02), "I can assist families in helping their children do well in school". The highest item in the Readiness section is $\mathrm{C} 103.87$ ( $\mathrm{SD}=0.77$ ), "I believe that social development of students may influence students' performance". The lowest score was $2.33(\mathrm{SD}=1.20)$ for item $\mathrm{C} 11$, "I attended a basic special education course

\subsection{The Relationships Between Attitudes and Readiness and Self-efficacy and Readiness}

A Pearson's correlation coefficient was used to determine the link between attitude and readiness to implement inclusive education and the relationship between self-efficacy and willingness to implement inclusive education. In addition, a Pearson correlation coefficient test may be performed to assess the connections between IV1 (attitude), IV2 (self-efficacy), and DV since the data is of normal distribution, according to the Kolmogorov-Smirnov test (Readiness).

The link between attitude and readiness for implementing inclusive education is substantial and moderately favorable $(r=.649, \rho<.001)$, indicating a relationship between attitude and readiness. Thus, an increase in positive attitudes would increase readiness.

The relationship between self-efficacy and readiness towards implementing inclusive education is significantly positive and moderate $(r=.594, \rho<.001)$, implying a relationship between self-efficacy and readiness. Thus, an increased self-efficacy would increase readiness.

\subsection{Regression Analysis}

The impact of attitudes and self-efficacy in predicting participants' willingness to adopt inclusive education was investigated using multiple regression analysis. Attitudes and self-efficacy are predictor factors, whereas preparedness is the criterion variable among teachers in mainstream primary schools in Hulu Selangor. Both independent variables and dependent variables have a linear connection. A significant regression equation was found $(\mathrm{F}(2,111)=62.215, \rho<.001)$, with an R2 of .529. Participants' predicted readiness towards the implementation of inclusive education is equal to $-1.118+.781$ (attitude) +.522 (self-efficacy). Participants' readiness to implement inclusive education increased .781 for each attitude and .522 for each self-efficacy. There is a significant predictive correlation of attitudes and self-efficacy on readiness to implement inclusive education among mainstream primary school teachers in Hulu Selangor.

Table 1. Regression Analysis

\begin{tabular}{ccccc}
\hline Model & $\mathbf{R}$ & $\mathbf{R}^{\mathbf{2}}$ & Adjusted R Square & Std. Error of the Estimate \\
\hline 1 & $.727^{\text {a }}$ & .529 & .520 & .44790 \\
\hline
\end{tabular}

a. Predictors: (Constant), Self-Efficacy, Attitude

Table 2. ANOVA

\begin{tabular}{ccccccc}
\hline & Model & Sum of Squares & df & Mean Square & F & Sig. \\
\hline \multirow{4}{*}{1} & Regression & 24.962 & 2 & 12.481 & 62.215 & $.000^{\mathrm{b}}$ \\
& Residual & 22.268 & 111 & .201 & & \\
& Total & 47.230 & 113 & & & \\
\hline
\end{tabular}

Table 3. MLR analysis

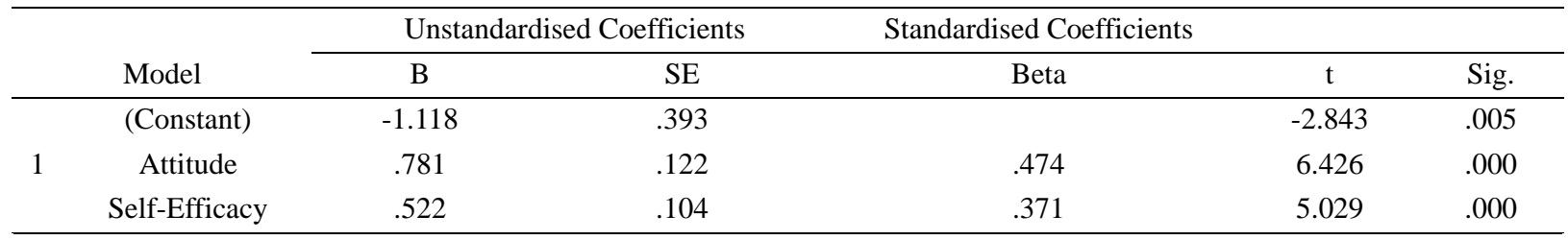

a. Dependent Variable: Readiness

\section{Discussion}

The average mean score for attitudes is 3.10 , which is considered to be in the middle range. With a mean score of 3.91, question A6, "I believe academic improvement is feasible in children with exceptional needs", had the highest mean score. Question "A7 (1.87) "I feel that children with exceptional needs should be put in special education classes" had the lowest mean score (1.87). The common response for teachers for items A7 (1.87) and item A20 (2.51) "Students with special needs should be included in regular education classrooms", shows that teachers have ambivalent feelings towards the placement of students with SEN students. However, item A5 (3.51) 
shows one of the highest mean levels in which teachers agree that although children differ intellectually, physically, and psychologically, they believe that all children can learn in most environments."

According to the result of this questionnaire, while most teachers believe that children with special needs should be placed in special education classrooms, most teachers also think they should be included in regular education classes. Despite their intellectual, physical, and psychological disparities, the vast majority of teachers believe that all children can learn in most situations. This ambivalence in attitude might suggest a lack of awareness on the part of the teachers. They may lack sufficient understanding of inclusive education and educating children with special needs to make a firm judgment on where children with special needs should be placed in the educational system. Interestingly, these ambivalent views on inclusion are echoed in Bailey et al.'s (2015) study of attitudes towards inclusive education in Malaysia. While most teachers $(80 \%)$ believe that inclusion is a desirable practise, teachers have a divided opinion on whether SEN students should possess the 'right' to be educated in a mainstream classroom. Bailey et al. (2014) indicated that inclusion was more an opportunity than a right as this statement is agreed by $95 \%$ of the teachers in their study. However, a vast majority (95\%) of teachers believed that students with special needs are best placed in special education classes, as reflected in the study.

The average mean score for Self-efficacy of teachers is 3.75 and is in the moderate range. The findings show a high mean value for item B8, indicating "I can control disruptive behaviour in the classroom". However, the low mean value (2.83) for item B7 "I am confident in my ability to prevent disruptive behaviour in the classroom before it occurs", could imply that teachers are more confident in managing disruptive behaviour when it happens rather than engaging in preventive strategies before those behaviours occur.

Gordon (2017), in studying the Effects of Teacher Self-Efficacy with the Inclusion of Students with Autism in General Education Classrooms, found that teachers acknowledge the challenges in controlling disruptive behaviour with autism. A participant stated that it is the biggest struggle in educating students with autism in an inclusive classroom. The statements reinforce that a teachers' self-efficacy would be questioned with the efforts of including students with autism, however other reports that participants made projected the efficacious sense that teachers would gain in implementing inclusive education in the classroom. As also shown in this study, it is possible that teachers are productive in some regions of inclusive education but less confident in others. This sentiment resonated in the Malaysian context, where Razali et al. (2013) found that teachers were not prepared to teach children with autism in their class because they did not know the characteristics of children with autism and did not understand the importance of inclusive education.

Regarding readiness, items 1-10 are based on readiness in terms of skills of teaching students with special needs, and items 11- 20 include knowledge on inclusive education programs. The mean for all items is 3.22 , which is in the moderate range. The mean for teaching students with special needs items is mostly higher than the knowledge subscale. These findings indicate that teachers believe that they are ready to have the skills to teach in an inclusive setting but are less prepared in terms of knowledge on inclusion and students with Special Needs. This finding reflects the results of an earlier study by Lai et al. (2017) on teachers' readiness to implement inclusive education. The study also found that teachers are more ready for skills than knowledge needed to teach in inclusive settings. The findings from both studies indicate that teachers have the skills but might not be prepared to teach in inclusive settings because they lack the knowledge to do so

The relationship between attitude and readiness towards implementing inclusive education is significantly positive and moderate $(r=.649, \rho<.001)$. Thus an increase in positive attitudes would increase readiness. Research in teachers' attitudes towards inclusive education begins on the plausible presupposition that a new policy, such as inclusive education, should be implemented in real-world practices. Thus, practitioners, in this case, teachers, are crucial in putting this new policy into action. Moreover, it is plausible that a teacher with negative attitudes towards implementing a particular approach might obstruct its realisation (Kielblock, 2018). Thus, teachers need to have positive attitudes towards implementing inclusive education to be more willing and ready to implement the policy. Some scholars argued that the attitude-practice relation is a common belief (Sharma \& Sokal, 2015) of attitude research in inclusive education. Therefore, teachers with more positive attitudes towards the inclusive policy and framework would be more likely to have the will and be ready to implement inclusive education.

Furthermore, empirical evidence proposes that teachers who have more positive attitudes towards inclusive education use more inclusive teaching strategies (Sharma \& Sokal, 2015). This finding is also reflected in the study by Khan (2011) on attitudes and knowledge of secondary school teachers' on inclusive education in Bangladesh. The study discovered that teachers committed to educating all students would go above and beyond 
to adjust their teaching methods to accommodate all pupils. Other researchers agree, arguing that a teacher's attitude toward inclusive education as a social justice project helps them become change agents (Hassan et al., 2017), boosting their willingness and preparedness to adopt inclusive education in their classrooms.

A teacher's commitment to a sense of social justice and their positive attitudes towards inclusive education would indicate that they would be ready and willing to go the extra mile in accommodating their learners in an inclusive classroom (Pantić \& Florian, 2015). Teachers need to shift their attitudes and beliefs, to realise that every child has been entrusted to schools to be rightly educated. Hence teachers need to explore ways of working with each child. They need to believe that mastering a wide range of instructional methods and how to apply them effectively is a good advantage (Rabi et al., 2018). The attitude change can be enhanced by providing support and training to teachers about inclusive education. When teachers show a high commitment to implementing inclusive education, they would be more willing and prepared to implement inclusive practices in the classroom. Black-Hawkins and Florian (2012) investigated teachers' craft expertise in implementing inclusive education in Scottish primary schools and concluded that teachers who demonstrate a commitment to fulfilling the needs of all children have a greater chance of adopting inclusive education. This finding further supports the theory that instructors with a positive attitude toward inclusion are more likely to be enthusiastic and ready to implement inclusive education in their classes using inclusive teaching approaches. In their research of Malaysian teachers' preparedness for inclusive education, Lai et al. (2017) found that mainstream instructors did not demonstrate an interest in understanding the requirements of the Inclusive Education Program and students with special needs. This apparent lack of interest might subsequently impact the efficiency when inclusive education is implemented. This study also found a link between teachers' attitudes and preparedness, it is essential to include these perspectives when assessing teachers' readiness to adopt Inclusive Education in Malaysia. Teachers with a good attitude and a solid commitment to implementation are more likely to be ready and prepared to teach inclusive classrooms.

The connection between self-efficacy and preparedness to undertake inclusive education is modest and significantly favourable $(\mathrm{r}=.594, \mathrm{P}<.001)$. As a result, increased self-efficacy leads to increased preparedness. Teachers who have a high level of teaching efficacy are more likely to be committed to teaching in a diverse classroom. Tschannen-Moran and Hoy (2007) noted that teachers' self-efficacy is a small idea with a significant impact. Acknowledgement of how teachers judge their capabilities in teaching students with SEN correlates with their attitudes, behaviour and preparedness to teach in inclusive classrooms. One of Themane and Thobejane's (2019) investigations to make education more inclusive is that instructors must act as change agents. If instructors think that all students can learn, they would be more ready to modify their methodology to accommodate the students when they teach. Florian (2012) echoes this conclusion, noticing the difficulties of an unpredictably changing instructional environment, which leaves instructors feeling inept and lacking the confidence needed to implement inclusive education. According to Themane and Thobejane (2019), teachers' suggestions have significant consequences. They are especially true in countries like South Africa, Zimbabwe and Malaysia, where inclusive education is still in its infancy (Mandina, 2012). Since self-efficacy in this study shows a predictive correlation towards readiness towards implementing inclusive education, self-efficacy should be considered in increasing the preparedness of mainstream primary school teachers towards inclusive education.

Individual self-efficacy beliefs influence how motivated and persevering people are when faced with challenges and hurdles (Bandura, 1977). As a result, those with firm self-efficacy beliefs are more likely to persist in difficult situations. In contrast, scepticism and ambiguity in their views are more likely to give up or reduce their efforts (Bandura, 1989). Moreover, self-efficacy beliefs might be shaped by individuals' judgments, thought processes and responses, when individuals interact within a specific environment (Bandura, 1977). For example, individuals who have the perception that they are underqualified or incompetent to manage a particular change in the climate might focus on their perceived inadequacy (Bandura 1981, 1989) instead of their capacity to grow amid challenges in the environment.

This scenario shows that teachers with high self-efficacy would be more willing and ready to take more risks and explore new methods to meet the needs of SEN children in an inclusive classroom. To ensure that the implementation of inclusive education in Malaysia is successful, it is in dire need of teachers who are more inclined to persist in utilising different instructional methods to provide students with SEN a fair chance at thriving in an inclusive classroom. Teachers need to be able to respond to challenging and stressful situations. Since the implementation of inclusive education is relatively recent in Malaysia, there are bound to be challenging situations that teachers have to manage. Teachers should perceive the implementation of inclusive education as a challenge rather than feel threatened by the stress and challenges that could occur in inclusive education. A strong sense of persistence and perseverance are vital for teachers to be willing and ready to 
undertake the challenges that come with teaching in an inclusive classroom

Sharma and Sokal (2015) used four factors to determine pre-service teachers' preparedness to teach in an inclusive classroom: attitudes, self-efficacy, worries, and interests of pre-service teachers. This study focuses on two of those elements, attitudes and self-efficacy. The findings show that a significant regression equation was found $(\mathrm{F}(2,111)=62.215, \rho<.001)$, with an R2 of .529. Participants' predicted readiness towards the implementation of inclusive education is equal to $-1.118+.781$ (attitude) +.522 (self-efficacy). Participants' readiness to implement inclusive education increased .781 for each attitude and .522 for each self-efficacy. Both attitude and self-efficacy were significant predictors of readiness towards implementing inclusive education, indicating a significant predictive correlation of attitudes and self-efficacy on readiness towards the implementation of inclusive education among mainstream primary school teachers in Hulu Selangor.

Teachers' readiness might break one of the most significant barriers in the implementation of inclusive education. There will be fewer barriers and challenges in successfully implementing inclusion education when teachers are ready and willing to teach in an inclusive environment. Despite that, it is essential to acknowledge that there could be many other reasons that underpin the fact that some SEN students face difficulties in academic and social interactions at school. This difficulty affects the child and possibly his classmates' social interactions and learning process in an inclusive classroom (Sharma \& Sokal, 2015). Many variables contribute to the difficulty of teaching in an inclusive classroom. For example, the lack of understanding and awareness of inclusive education might be a barrier to inclusion. Furthermore, when special education teachers and general education teachers fail to reach a mutual agreement, it is challenging to implement inclusive education successfully. In addition, teachers' readiness to teach Special Needs students in an inclusive setting might be a significant cause when the implementation of inclusive education programs fails (Rabi et al., 2018).

Without the desire and preparedness of researchers, it would be more challenging to transform new legislation into inclusive practices properly. Teachers' attitudes on their responsibility to educate and care for children with special needs are critical in moving schools away from segregation and progressing towards inclusivity in the educational system. Findings reflect that working effectively in inclusive settings requires positive attitudes and a sense of self-efficacy towards SEN students. As a result, it's critical to look into how attitudes and self-efficacy affect the implementation of inclusive education. Because this study shows that the two components have a role in predicting teachers' preparation to implement inclusive education, we must include them when assessing teachers' preparedness.

\section{Conclusion}

In conclusion, it is promising that at the infancy stage of inclusive education in Malaysia, teachers' attitudes, self-efficacy, and readiness for inclusive education in a relatively small town in Malaysia are at moderate levels. This means that there is already some awareness among teachers in mainstream schools, even in rural areas in Malaysia. The study has projected attitudes and self-efficacy to predict factors in teachers' readiness to implement inclusive education. Therefore, the promotion of positive attitudes and high self-efficacy should be considered when contemplating a teacher's readiness. Inclusion awareness and training programs can include elements of building up positive attitudes and self-efficacy to prepare teachers to be more willing and ready to be a significant part of inclusive education. It is commendable that although this study indicates that teachers believe they are less prepared in terms of knowledge on inclusion and students with Special Needs, they do think they are ready and willing in terms of skills to teach in an inclusive setting. Hence, positive attitudes and high self-efficacy can be components to consider in boosting teachers' readiness to implement inclusive education.

Every child should have a right to quality education. More inclusive programs in mainstream schools would be needed with a zero-reject policy and the rising numbers of students with special needs. Hence teachers' readiness to implement inclusive education is a highly relevant issue to be investigated. It would not be fair to accept all children into the mainstream schooling system without preparing teachers on ways to teach them. Attitudes and self-efficacy could be considered when investigating teachers' readiness to implement inclusive education in the future.

\section{Implication}

Roles of attitudes and self-efficacy on teachers' readiness must be investigated so that resource content could be more explicitly and purposefully developed to develop teachers' understanding of SEN students and recommended inclusion practices. This endeavour could subsequently impact other children's awareness and acceptance of disabilities and peers with special needs (Hadadian \& Hargrove, 2001), as teachers are the primary role models for students in a classroom. Since Zero Reject Policy in Malaysia would eventually involve increasing schools adopting the inclusive education model, it is crucial to spread awareness on inclusive 
education and what it entails. There are still low levels of awareness among communities in Malaysia, especially in smaller towns and rural areas. Most teachers are less aware of the inclusive framework and strategies to teach students with special needs in an inclusive setting. The findings from this study can also be considered when designing courses and in-service training programs for teachers on inclusive education.

This study could be conducted on a bigger scale, employing mixed-methods methodology, in more diverse settings, like urban areas, other districts and states in Malaysia, all of which are demographically and geographically diverse. It would be interesting to observe what the findings would yield by creating a standardised measuring instrument to utilise in schools to gauge levels of readiness in schools across Malaysia. The dimensions can pertain to physical spaces, administrators, staff members, and other children with SEN. A comparison study between states in Malaysia in their levels of implementation of inclusive education. In Malaysia's incubation period of the Zero Reject Policy, it is pertinent to investigate teachers' readiness in Malaysia to contribute to the body of research on Zero reject policy and inclusive education. In addition, readiness can be explored regarding other aspects like school climate or collaboration. Teachers in Malaysia are encouraged to do more action research to enrich data. Qualitative studies that address the implementation of inclusive education would also be beneficial.

\section{References}

Agbenyega, J. S., \& Klibthong, S. (2015). Transforming Thai preschool teachers' knowledge on inclusive practice: A collaborative inquiry. Australian Journal of Teacher Education, 40(7), 57-69. https://doi.org/10.14221/ajte.2015v40n7.5

Ajzen, I., \& Fishbein, M. (1980). Understanding attitudes and predicting social behavior. Englewood Cliffs; NJ: Prentice-Hall.

Ali, M. M., Mustapha, R., \& Jelas, Z. M. (2006). An Empirical Study on Teachers' Perceptions towards Inclusive Education in Malaysia. International Journal of Special Education, 21(3), 36-44.

Azorín, C., \& Ainscow, M. (2020). Guiding schools on their journey towards inclusion. International Journal of Inclusive Education, 24(1), 58-76. https://doi.org/10.1080/13603116.2018.1450900

Azmi, S. (2018). Zero Reject Policy for All Students. New Straits Times. Retrieved from https://www.nst.com.my/news/nation/2018/12/442345/zero-rejectpolicy-all-students.

Bailey, L., Nomanbhoy, A., \& Tubpun, T. (2015). Inclusive education: Teacher perspectives from Malaysia. $\begin{array}{llll}\text { International Journal of Inclusive } & \text { Education, }\end{array}$ https://doi.org/10.1080/13603116.2014.957739

Baker, B. (2002). The hunt for disability: The new eugenics and the normalisation of school children. Teachers College Record, 104, 663-704. https://doi.org/10.1111/1467-9620.00175

Bandura, A. (1977). Self-efficacy: Toward a unifying theory of behavioral change. Psychological Review, 84(2), 191-215. https://doi.org/10.1037/0033-295X.84.2.191

Bandura, A. (1989). Regulation of cognitive processes through perceived self-efficacy. Developmental Psychology, 25(5), 729-735. https://doi.org/10.1037/0012-1649.25.5.729

Bandura, A. (1990). Reflections on nonability determinants of competence.

Bandura, A. (1997). Self-Efficacy: The Exercise of Control. New York: W.H. Freeman and Company.

Beacham, N., \& Rouse, M. (2012). Student teachers' attitudes and beliefs about inclusion and inclusive practice. Journal of Research in Special Educational Needs, 12(1), 3-11. https://doi.org/10.1111/j.1471-3802.2010.01194.x

Black-Hawkins, K., \& Florian, L. (2012). Classroom teachers' craft knowledge of their inclusive practice. Teachers and Teaching, 18(5), 567-584. https://doi.org/10.1080/13540602.2012.709732

Black, W. R., \& Simon, M. D. (2014). Leadership for all students: Planning for more inclusive school practices. International Journal of Educational Leadership Preparation, 9(2), 153-172.

Buford, S., \& Casey, L. (2012) Attitudes of Teachers Regarding Their Preparedness to Teach Students with Special. Delta Journal of Education, 2(2), 16-30.

Cate, Markova, Krischler, \& Krolak-Schwerdt. (2018) Promoting InclusiveEducation: The Role of Teachers' Competence and Attitudes. Insights into Learning Disabilities, 15(1), 49-63.

Ching, S. M. (2009). Employment of people with disabilities in Malaysia: Drivers and Inhibiters. The Second 
Malaysian Conference on Rehabilitation, Malaysia.

Corsini, R. J., \& Auerbach, A. J. (1998). Concise encyclopedia of psychology.

Di Gennaro, D. C., Pace, E. M., Zollo, I., \& Aiello, P. (2014). Teacher Capacity Building through Critical Reflective Practice for the Promotion of Inclusive Education. Problems of Education in the 21 st Century, 60, 54-66. https://doi.org/10.33225/pec/14.60.54

Florian, L., \& Black-Hawkins, K. (2011). Exploring inclusive pedagogy. British educational research journal, 37(5), 813-828. https://doi.org/10.1080/01411926.2010.501096

Florian, L., Young, K., \& Rouse, M. (2010). Preparing teachers for inclusive and diverse educational environments: Studying curricular reform in an initial teacher education course. International Journal of Inclusive Education, 14(7), 709-722. https://doi.org/10.1080/13603111003778536

Goodall, C. (2015). How do we create ASD-friendly schools? A dilemma of placement. Support for Learning, 30(4), 305-326. https://doi.org/10.1111/1467-9604.12104

Gordon, T. Q. (2017). The Effects of Teacher Self-Efficacy with the Inclusion of Students with Autism in General Education Classrooms (PhD Thesis). Loyola University Chicago.

Hadadian, A., \& Hargrove, L. (2001). Childcare Perspectives on Inclusion: Do We Have a Long Way to Go? Infant-Toddler Intervention: The Transdisciplinary Journal, 11(1), 49-58.

Hassan, A. E., Hassan, H., Adhabi, A., \& Wright-Jones, L. (2017). The Impact of Inclusion Setting on Social Interaction and Psychological Adjustment of Students with Disabilities. International Journal of Scientific Research in Science and Technology, 4, 121-128.

Hay, J. F., Smit, J., \& Paulsen, M. (2001). Teacher preparedness for inclusive education. South Africa Journal of Education, 21(4), 213-218.

Khan, T. A. (2011). Investigation of secondary school teachers' attitudes towards and knowledge about inclusive education in Bangladesh (Master Thesis). University of Canterbury.

Kielblock, S. (2018). Inclusive Education for All: Development of an Instrument to Measure the Teachers' Attitudes (PhD Thesis). Macquarie University Sydney.

Killoran, I., Woronko, D., \& Zaretsky, H. (2014). Exploring pre service teachers' attitudes towards inclusion. International Journal of Inclusive Education, $18(4), \quad 427-442$. https://doi.org/10.1080/13603116.2013.784367

Lai, C. S., Lee, M. F., Nor Lisa, S., Mimi Mohaffyza, M., \& Kahirol, M. S. (2017). Involvement of Mainstream Teachers in Inclusive Education: Are We Ready? Pertanika Journal of Social Sciences \& Humanities, 25(s), 205-214.

Lee, L. W., \& Low, H. M. (2013). 'Unconscious' inclusion of students with learning disabilities in a Malaysian mainstream primary school: Teachers' perspectives. Journal of Research in Special Educational Needs, 13(3), 218-228. https://doi.org/10.1111/j.1471-3802.2012.01250.x

Leonard, N., \& Smyth, S. (2020). Does training matter? Exploring teachers' attitudes towards the inclusion of children with autism spectrum disorder in mainstream education in Ireland. International Journal of Inclusive Education. https://doi.org/10.1080/13603116.2020.1718221

Loreman, T., Sharma, U., \& Forlin, C. (2013). Do pre-service teachers feel ready to teach in inclusive classrooms? A four country study of teaching self-efficacy. Australian Journal of Teacher Education (Online), 38(1), 27-44. https://doi.org/10.14221/ajte.2013v38n1.10

MacFarlane, K., \& Woolfson, L. M. (2013). Teacher attitudes and behavior toward the inclusion of children with social, emotional and behavioral difficulties in mainstream schools: An application of the theory of planned behavior. Teaching and teacher education, 29, 46-52. https://doi.org/10.1016/j.tate.2012.08.006

Mandina, S. (2012). Bachelor of education in service teacher trainees' perceptions and attitudes on inclusive education in Zimbabwe. Asian Social Science, 8(13), 227-232. https://doi.org/10.5539/ass.v8n13p227

Ministry of Education Malaysia. (2017). Data Pendidikan Khas. Putrajaya: Ministry of Education Malaysia.

Ministry Of Education Malaysia. (2018). Malaysian Education Statistics 2017. Putrajaya: Ministry of Education Malaysia.

Pantić, N., \& Florian, L. (2015). Developing teachers as agents of inclusion and social justice. Education Inquiry, 
6(3), 333-351. https://doi.org/10.3402/edui.v6.27311

Razali, N. M., Toran, H., Kamaralzaman, S., Salleh, N. M., \& Yasin, M. H. M. (2013). Teachers' perceptions of including children with autism in a preschool. Asian Social Science, 9(12), 261. https://doi.org/10.5539/ass.v9n12p261

Rabi, N. M., Ghazali, N. H. C. M., Rohaizad, N. A. A., \& Zulkefli, M. Y. (2018). Readiness of pre-service teacher to teach student with special needs through inclusive education course. International Journal of Academic Research in Progressive Education and Development, 7(4), 200-210. https://doi.org/10.6007/IJARPED/v7-i4/4847

Ricci, L. A., Benis Scheier-Dolberg, S., \& Perkins, B. K. (2020). Transforming triads for inclusion: Understanding frames of reference of special educators, general educators, and administrators engaging in collaboration for inclusion of all learners. International Journal of Inclusive Education, 1-14. https://doi.org/10.1080/13603116.2019.1699609

Rosenberg, M. J., Hovland, C. I., McGuire, W. J., Abelson, R. P., \& Brehm, J. W. (1960). Attitude organisation and change: An analysis of consistency among attitude components. Yale studies in attitude and communication, 3 .

Rouse, A. G. (2018). Instruction for students with special needs. In S. Graham, C. A. MacArthur, \& M. Hebert (Eds.), Best practices in writing instruction (pp. 361-405). The Guilford Press.

Saloviita, T. (2020). Attitudes of Teachers towards Inclusive Education in Finland. Scandinavian Journal of Educational Research, 64(2), 270-282. https://doi.org/10.1080/00313831.2018.1541819

Schunk, D. H., \& Pajares, F. (2005). Competence perceptions and academic functioning. In A. J. Elliot, \& C. S. Dweck (Eds.), Handbook of competence and motivation (pp. 141-163). New York, NY: Guilford Scott (2016)

Sharma, U., Forlin, C., \& Loreman, T. (2008). Impact of training on pre-service teachers' attitudes and concerns about inclusive education and sentiments about persons with disabilities. Disability \& society, 23(7), 773-785. https://doi.org/10.1080/09687590802469271

Sharma, U., \& George, S. (2016). Understanding teacher self-efficacy to teach in inclusive classrooms. In Asia-pacific perspectives on teacher self-efficacy (pp. 37-51). Brill Sense. https://doi.org/10.1007/978-94-6300-521-0_3

Sharma, U., \& Sokal, L. (2015). Can Teachers' Self-Reported Efficacy, Concerns, and Attitudes Toward Inclusion Scores Predict Their Actual Inclusive Classroom Practices? Australasian Journal of Special Education, 40(1), 21-38. https://doi.org/10.1017/jse.2015.14

Shevlin, M., Winter, E., \& Flynn, P. (2013). Developing inclusive practice: Teacher perceptions of opportunities and constraints in the Republic of Ireland. International Journal of Inclusive Education, 17(10), 1119-1133. https://doi.org/10.1080/13603116.2012.742143

Sofian, N. M., Hashim, A. S., \& Sarlan, A. (2020). Analysis of Multimedia Elements Criteria Using AHP Method. In F. Saeed, F. Mohammed, \& A. Al-Nahari (Eds.), International Conference of Reliable Information and Communication Technology (pp. 891-902). Springer. https://doi.org/10.1007/978-3-030-70713-2_80

Subban, P., Round, P., \& Sharma, U. (2021). 'I can because I think I can': An investigation into Victorian secondary school teacher's self-efficacy beliefs regarding the inclusion of students with disabilities. International Journal of Inclusive Education, 348-361. https://doi.org/10.1080/13603116.2018.1550816

Sukumaran, S., Loveridge, J., \& Green, V. A. (2015). Inclusion in Malaysian integrated preschools. International Journal of Inclusive Education, 19(8), 821-844. https://doi.org/10.1080/13603116.2014.981229

Teng, K. Y. (2016). Contributions of Inclusive Education Programme, Teachers Attitudes and Efficacy on Social Skills among Students with Autism Spectrum Disorder (PhD Thesis). Universiti Teknologi Malaysia.

Themane, M., \& Thobejane, H. R. (2019). Teachers as change agents in making teaching inclusive in some selected rural schools of Limpopo Province, South Africa: Implications for teacher education. International Journal of Inclusive Education, 23(4), 1-16. https://doi.org/10.1080/13603116.2018.1434690

Tschannen-Moran, M., \& Hoy, A. W. (2007). The differential antecedents of self-efficacy beliefs of novice and experienced teachers. Teaching and Teacher Education, 23(6), 944-956. https://doi.org/10.1016/j.tate.2006.05.003 
Umhoefer, D., Beyer, R., \& Vargas, T. M. (2013). Theory into practice: Enhancing general physical educators' teacher efficacy when working with all students. Strategies: A Journal for Physical and Sports Educators, 25(7), 32-34. https://doi.org/10.1080/08924562.2012.10590981

UNESCO. (1994). Final Report: World Conference on Special Needs Education: Access and Quality. UNESCO.

UNESCO. (2015). Education for all 2000-2015: Achievements and challenges. UNESCO.

Waitoller, F. R., \& Artiles, A. J. (2013). A decade of professional development research for inclusive education: A critical review and notes for a research program. Review of Educational Research, 83(3), 319-356. https://doi.org/10.3102/0034654313483905

\section{Copyrights}

Copyright for this article is retained by the author(s), with first publication rights granted to the journal.

This is an open-access article distributed under the terms and conditions of the Creative Commons Attribution license (http://creativecommons.org/licenses/by/4.0/). 